\title{
Aberrant actin depolymerization triggers the pyrin inflammasome and autoinflammatory disease that is dependent on IL-18, not IL-1ß
}

\author{
Man Lyang Kim, ${ }^{1,8}$ Jae Jin Chae, ${ }^{5}$ Yong Hwan Park, ${ }^{5}$ Dominic De Nardo, ${ }^{1,8}$ \\ Roslynn A. Stirzaker, ${ }^{2}$ Hyun-Ja Ko, ${ }^{3}$ Hazel Tye, ${ }^{1}$ Louise Cengia, ${ }^{2}$ \\ Ladina DiRago, ${ }^{2}$ Donald Metcalf, ${ }^{2,8}$ Andrew W. Roberts, ${ }^{2,8}$ \\ Daniel L. Kastner, ${ }^{5}$ Andrew M. Lew, ${ }^{3,8}$ Dena Lyras, ${ }^{6}$ Benjamin T. Kile,, 8 \\ Ben A. Croker, ${ }^{7 *}$ and Seth L. Masters ${ }^{1,8 *}$
}

\footnotetext{
'Division of Inflammation, ${ }^{2}$ Division of Cancer and Hematology, ${ }^{3}$ Division of Immunology, and ${ }^{4}$ ACRF Chemical Biology Division, The Walter and Eliza Hall Institute of Medical Research, Parkville, Victoria 3052, Australia 5 Inflammatory Disease Section, Metabolic, Cardiovascular, and Inflammatory Disease Genomics Branch, National Human Genome Research Institute, National Institutes of Health, Bethesda, MD 20892 ${ }^{6}$ Department of Microbiology, Monash University, Clayton, Victoria 3800, Australia ${ }^{7}$ Division of Hematology/Oncology, Boston Children's Hospital, Harvard Medical School, Boston, MA 02115 ${ }^{8}$ Department of Medical Biology, The University of Melbourne, Parkville, Victoria 3010, Australia
}

Gain-of-function mutations that activate the innate immune system can cause systemic autoinflammatory diseases associated with increased IL-1 $\beta$ production. This cytokine is activated identically to IL-18 by an intracellular protein complex known as the inflammasome; however, IL-18 has not yet been specifically implicated in the pathogenesis of hereditary autoinflammatory disorders. We have now identified an autoinflammatory disease in mice driven by IL-18, but not IL-1及, resulting from an inactivating mutation of the actindepolymerizing cofactor Wdr1. This perturbation of actin polymerization leads to systemic autoinflammation that is reduced when IL-18 is deleted but not when IL-1 signaling is removed. Remarkably, inflammasome activation in mature macrophages is unaltered, but IL-18 production from monocytes is greatly exaggerated, and depletion of monocytes in vivo prevents the disease. Small-molecule inhibition of actin polymerization can remove potential danger signals from the system and prevents monocyte IL-18 production. Finally, we show that the inflammasome sensor of actin dynamics in this system requires caspase-1, apoptosisassociated speck-like protein containing a caspase recruitment domain, and the innate immune receptor pyrin. Previously, perturbation of actin polymerization by pathogens was shown to activate the pyrin inflammasome, so our data now extend this guard hypothesis to host-regulated actin-dependent processes and autoinflammatory disease.

\section{CORRESPONDENCE}

Seth L. Masters:

masters@wehi.edu.au

Abbreviations used: ASC, apoptosis-associated speck-like protein containing a caspase recruitment domain; DAMP, danger-associated molecular pattern; DT, diphtheria toxin; FLDM, fetal liver-derived monocyte; FMF, familial Mediterranean fever.
Autoinflammatory syndromes are caused by dysregulation of the innate immune system, frequently affecting the inflammasome or other pathogen recognition pathways and leading to the overproduction of active IL-1 $\beta$ and IL-18 (Masters et al., 2009). To date, there are at least 12 known genetic causes of autoinflammatory disease, including familial Mediterranean fever (FMF), hyper-IgD syndrome, and cryopyrinassociated periodic syndrome. Therapeutic options for these diseases include nonsteroidal antiinflammatory drugs, corticosteroids, colchicine

*B.A. Croker and S.L. Masters contributed equally to this paper. (for FMF), anti-TNF, and direct blockade of IL-1, which can be highly efficacious (Masters et al., 2009; Caso et al., 2013). IL-18 and IL-1 $\beta$ are produced in many cells, including monocytes and macrophages (Okamura et al., 1995; Ushio et al., 1996). IL-18 and IL-1 $\beta$ are produced as precursors and do not have a signal peptide to facilitate their secretion; instead, they are activated and released extracellularly as

2015 Kim et al. This article is distributed under the terms of an AttributionNoncommercial-Share Alike-No Mirror Sites license for the first six months after the publication date (see http://www.rupress.org/terms). After six months it is available under a Creative Commons License (Attribution-NoncommercialShare Alike 3.0 Unported license, as described at http://creativecommons.org/ licenses/by-nc-sa/3.0/). 

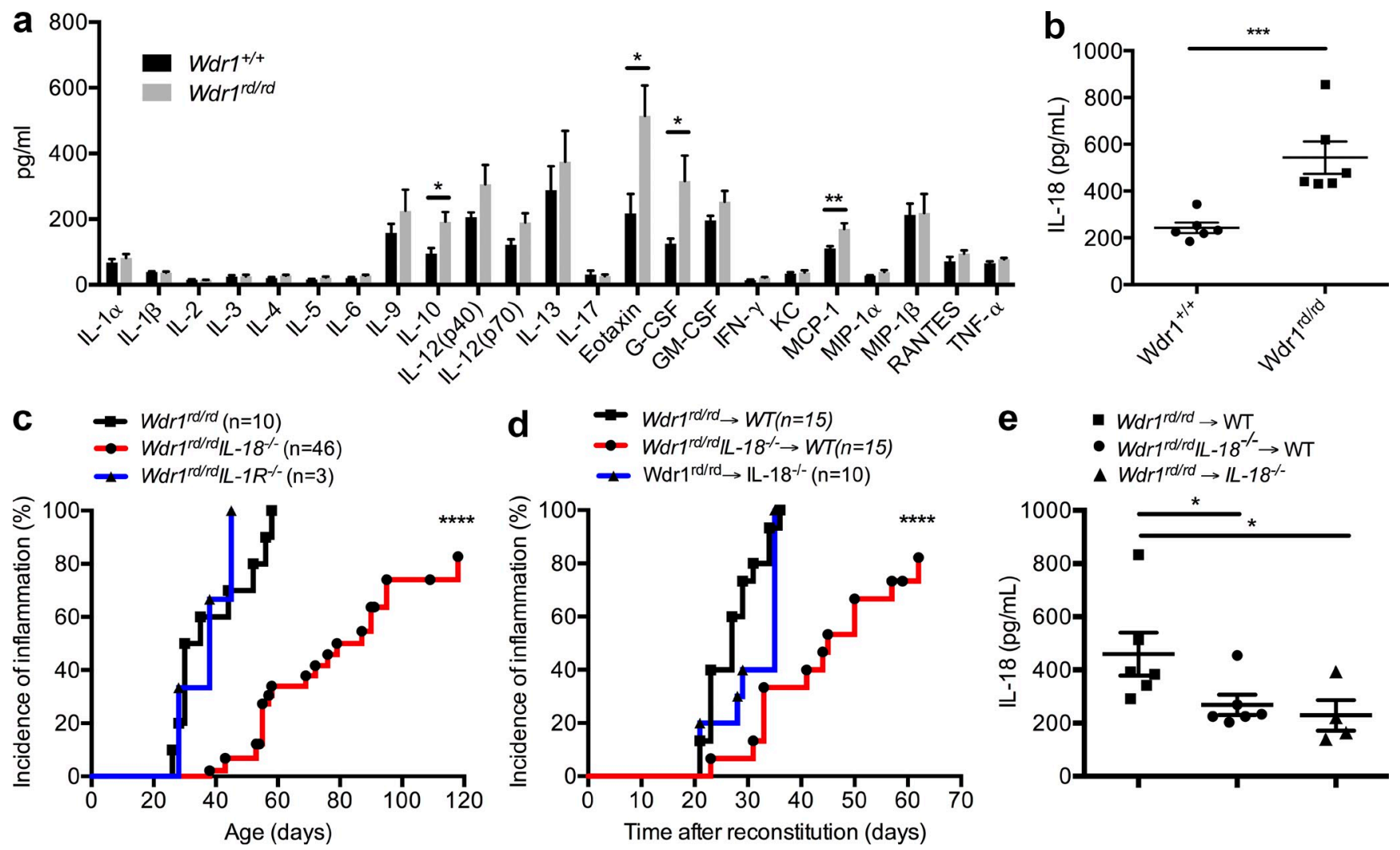

Figure 1. Autoinflammatory disease in $W d r r^{r d / r d}$ mice is IL-1 independent, but IL-18 dependent. (a and b) Serum cytokines/chemokines from wild-type $\left(W d r 1^{+++}\right)$and Wdr rrd/rd mice were analyzed by Bioplex (a) or for IL-1 $\beta$ and IL-18 by ELISA (b). $n=5-6 .{ }^{*}, \mathrm{P}<0.05 ;{ }^{* *}, \mathrm{P}<0.01 ;{ }^{* * *}, \mathrm{P}<0.001$ by unpaired $t$ test, corrected for multiple comparisons. (c) Incidence of inflammation in tail or ears for $W d r r^{r d / r d}$, Wdr $r^{r d / r d} / L-1 R^{-/-}$, or Wdr $7^{r d / r d} / L-18^{-/-}$mice. ${ }^{* * *}$, $P<0.0001$ by Gehan-Breslow-Wilcoxon test. (d) Incidence of inflammation after reconstitution of lethally irradiated mice with BM of the indicated genotypes (donor BM $\rightarrow$ irradiated host). ${ }^{* * *}, \mathrm{P}<0.0001$ by Gehan-Breslow-Wilcoxon test. (e) Serum IL-18 from the mice shown in panel $d$ was analyzed by ELISA. $n=4$ or 6 . Error bars represent means \pm SEM. ${ }^{*}, \mathrm{P}<0.05$ by one-tailed unpaired $t$ test. Except for disease incidence, all data are representative of two to four independent experiments.

mature proteins after cleavage by caspase-1 (Li et al., 1995; Ghayur et al., 1997; Gu et al., 1997). Despite these similarities, there is no known hereditary autoinflammatory disease where the pathology is caused exclusively by IL-18.

The inflammasome is an intracellular molecular platform that forms in response to pathogen- or danger-associated molecular patterns (DAMPs), leading to recruitment and activation of caspase-1 (Martinon et al., 2002; Schroder and Tschopp, 2010). A growing number of inflammasomes have been reported, each nucleated by a different innate immune receptor, such as NLRP1 (Martinon et al., 2000; Boyden and Dietrich, 2006), NLRP3 (Agostini et al., 2004), NLRC4 (Franchi et al., 2006), pyrin (Chae et al., 2011), and AIM2 (Hornung et al., 2009). Apoptosis-associated speck-like protein containing a caspase recruitment domain (ASC) is a key adaptor used by most of these innate immune receptors to interact with and recruit caspase-1 (Srinivasula et al., 2002). Activating mutations in NLRP3 result in increased IL-1 $\beta$ and IL-18 production, which can be prevented in mice by deleting caspase-1 or ASC. Furthermore, deleting either the IL-18R or the IL-1R can both independently protect mice from this NLRP3-mediated autoinflammatory disease (Brydges et al., 2013). For the FMF protein, pyrin, activating mutations induce ASC-dependent but NLRP3-independent IL-1 $\beta$ activation and cause severe autoinflammation in mice (Chae et al., 2011). Interestingly, pyrin interacts with ASC, microtubules, and actin filaments (Mansfield et al., 2001; Richards et al., 2001; Waite et al., 2009), and it has recently been shown that modification of RhoGTPases by bacterial toxins can trigger the pyrin inflammasome, perhaps via modulation of actin dynamics (Xu et al., 2014). This raises the fascinating prospect of a link between perturbations in the actin cytoskeleton and autoinflammatory disease.

Wdr1 is required for disassembly of actin filaments in conjunction with the actin-depolymerizing factor/cofilin family of proteins. Mice homozygous for a hypomorphic allele of Wdr1 (Wdr $\left.1^{r d / r d}\right)$ exhibit spontaneous autoinflammatory disease and thrombocytopenia (Kile et al., 2007). Both defects have been suggested to result from a disruption in actin dynamics. Thrombocytopenia results from defects in megakaryocytes, a cell type that is entirely dependent on a functional cytoskeleton to shed platelets (Patel et al., 2005). Wdr1 mutant mice also exhibit neutrophilia; however, the critical inflammatory mediators and cell types important for the development 

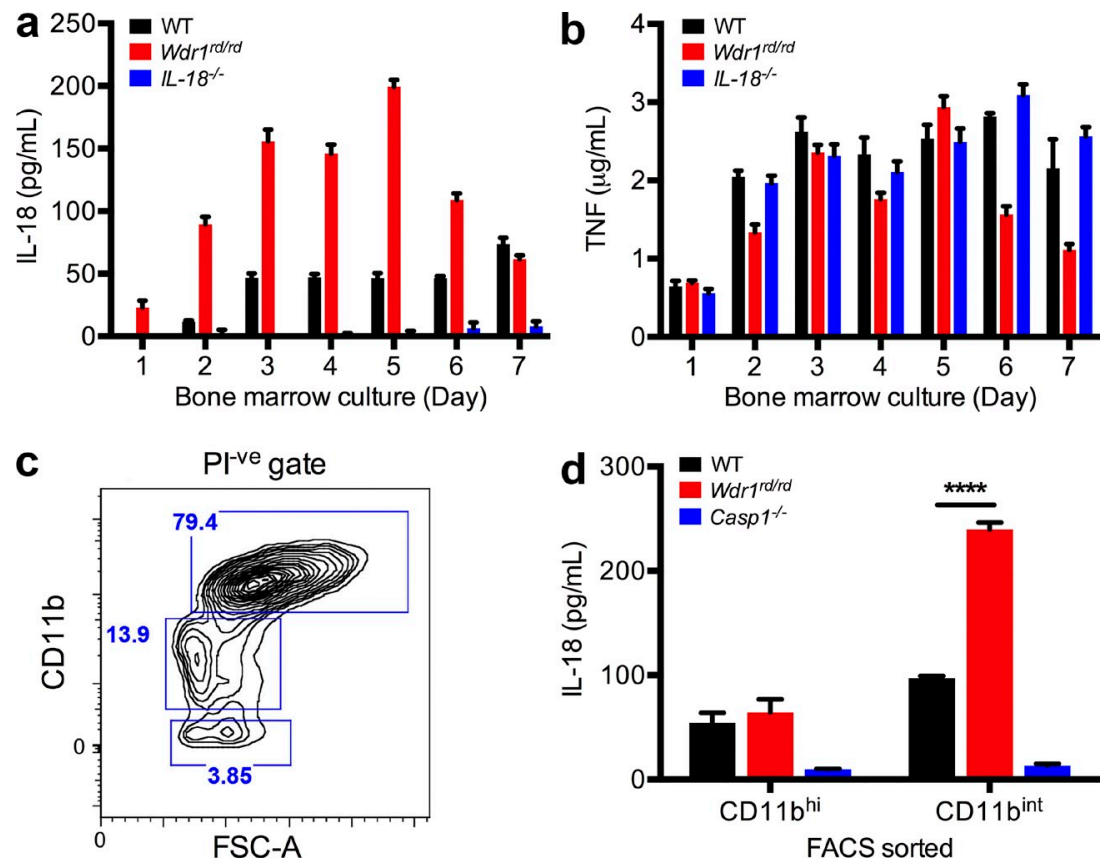

Figure 2. LPS-induced IL-18 secretion from $W d r 1^{r d / r d}$ monocytes, not macrophages. (a and b) BM from WT, Wdr $7^{r d / r d}$ or $I L-18^{-/-}$mice was cultured in L929 cell-conditioned medium for $1-7$ d. $10^{5}$ cells from day $1-7$ cultures were incubated with $1 \mu \mathrm{g} / \mathrm{ml}$ LPS. $48 \mathrm{~h}$ after stimulation, culture supernatants were harvested and assayed by ELISA for IL-18 (a) and TNF (b). Error bars represent SEM of two technical replicates of two biological duplicates. (c and d) BM from WT, Wdr $7^{\text {rddrd }}$, or caspase-1-1- mice was cultured in L929 cell-conditioned medium for $4 \mathrm{~d}$. (c) Propidium iodide negative ( $\left.\mathrm{Pl}^{-\mathrm{ve}}\right)$ and $\mathrm{CD} 11 \mathrm{~b}^{\text {hi }}$ or CD11bint/low populations indicated by blue boxes were sorted by flow cytometry. FSC-A, forward scatter A. (d) $5 \times 10^{4}$ cells were treated with $1 \mu \mathrm{g} / \mathrm{ml}$ LPS for $48 \mathrm{~h}$. Secreted IL-18 was measured as in panel a. Error bars represent SEM of three technical replicates of two biological duplicates. ${ }^{* * *}, P<0.0001$ by unpaired $t$ test. All data are representative of two independent experiments. of inflammation in this genetic condition are unclear (Kile et al., 2007). Intriguingly, Wdr1 was found to be secreted after caspase-1 activation (Keller et al., 2008).

We examined the role of key inflammatory mediators that drive autoinflammation in $W d r 1^{r d / r d}$ mice and demonstrated that this disease is IL-18 dependent, but IL-1 independent. As expected, this IL-18 is produced by the inflammasome; however, it is not produced from neutrophils or macrophages, but instead only from monocytes. Finally, we found that the autoinflammatory disease was mediated by pyrin, providing evidence that this innate immune receptor recognizes alterations in the actin polymerization pathway.

\section{RESULTS}

\section{Autoinflammatory disease in $W d r 1^{r d / r d}$ mice} is IL-1 independent, but IL-18 dependent

To identify the drivers of autoinflammation in $W d r 1^{r d / r d}$ mice, we measured serum cytokines and chemokines by Bio-Plex and ELISA (Fig. 1, a and b). IL-10, IL-18, G-CSF, Eotaxin, and MCP-1/CCL2 were found to be significantly elevated in serum from $W d r 1^{r d / r d}$ mice relative to that of wild-type littermates.

Given the increased neutrophil counts in BM, peripheral blood, and inflammatory lesions, we hypothesized that neutrophils are the principal cell types for initiating inflammation and are related to the elevated levels of serum Eotaxin, MCP-1, and G-CSF. In particular, G-CSF promotes the proliferation, differentiation, function, and survival of neutrophil precursors and mature neutrophils (Metcalf, 1985). We therefore generated G-CSF-deficient $W d r 1^{r d / r d}$ mice $\left(W d r 1^{r d / r d} G-C S F^{-/-}\right.$) to investigate the role of neutrophils in the development of autoinflammation. Despite an $80 \%$ reduction in circulating neutrophils for $W d r 1^{r d / r d} G-C S F^{-/-}$mice, autoinflammation developed at a similar rate and severity as in $W d r 1^{r d / r d}$ mice (unpublished data). This result suggests that neutrophilia and cytokines that promote neutrophilia (G-CSF, Eotaxin, and MCP-1) are not important for initiation of autoinflammation in $W d r 1^{r d / r d}$ mice.

The cutaneous inflammatory pathology of $W d r 1^{r d / r d}$ mice displayed features reminiscent of TNF- and IL-1 $\beta$-dependent diseases in humans. We therefore generated TNFR-deficient $W d r 1^{r d / r d}$ mice $\left(W d r 1^{r d / r d} T_{N F R}{ }^{-/-}\right.$), and although the neutrophil count was reduced, the incidence of autoinflammatory disease remained unchanged (unpublished data). We also generated IL-1R-deficient $W d r 1^{r d / r d}$ mice $\left(W d r 1^{r d / r d} I L-1 R^{-/-}\right)$, and again, the pathological manifestations and onset of inflammatory disease were not altered (Fig. 1 c). Finally, we tested the influence of IL-18, which is elevated in the serum of $W d r 1^{r d / r d}$ mice, has significant effects on neutrophil function, and is associated with inflammatory pathology of the skin (Leung et al., 2001; Wittmann et al., 2009). Unlike the previous genetic crosses, $W d r r^{r d / r d} I L-18^{-/-}$mice display a delayed onset of autoinflammatory disease (Fig. $1 \mathrm{c}$ ). These data show that the autoinflammatory disease in $W d r 1^{r d / r d}$ mice is regulated by IL-18. This is the first known example of a genetic autoinflammatory disease that is mediated by IL-18 but not IL-1 $\beta$.

\section{IL-18 from the hematopoietic compartment contributes to disease in $W d r 1^{r d / r d}$ mice}

We previously reported that the autoinflammatory disease in $W d r 1^{r d / r d}$ mice is BM intrinsic (Kile et al., 2007). To establish whether the pathogenic IL-18 observed in these animals derives from hematopoietic cells, we generated BM chimeras by transplanting unfractionated BM cells into lethally irradiated recipients. Consistent with our previous study (Kile et al., 2007), transfer of $W d r 1^{r d / r d} \mathrm{BM}$ into wild-type recipients triggered autoinflammatory disease a median of $22 \mathrm{~d}$ after 
a
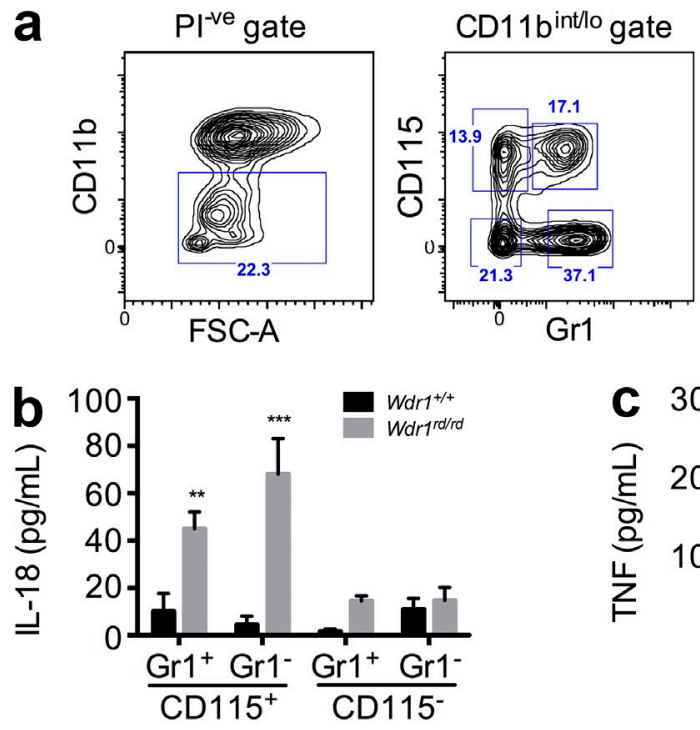

d

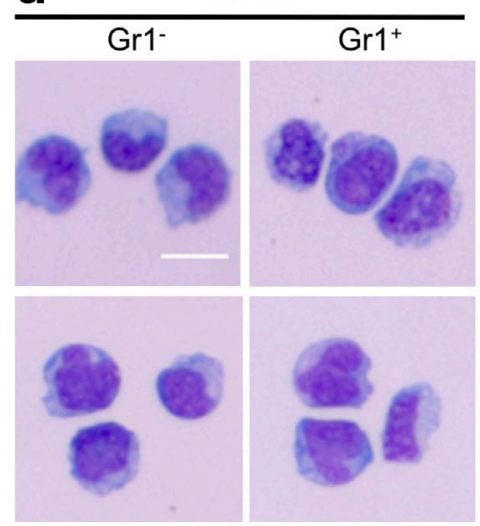

$\mathrm{CD}^{115^{+}}$

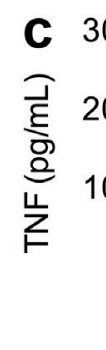

Figure 3. Increased IL-18 production from Wdr $1^{\text {rd/rd }}$ CD $11 b^{\text {int }}$ CD $115^{+}$monocytes. (a) BM

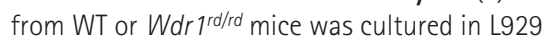
cell-conditioned medium for $4 \mathrm{~d}$. Propidium iodide negative (PI-ve) and CD11 bint/low populations were gated (blue box; left). FSC-A, forward scatter A. Based on CD115(M-CSFR) and Gr1 immunostaining, four subsets of CD11bint/low populations were sorted by flow cytometry (blue boxes; right). ( $b$ and c) $5 \times 10^{4}$ cells from each sorted population were incubated with $1 \mu \mathrm{g} / \mathrm{ml}$ LPS. $48 \mathrm{~h}$ after stimulation, culture supernatants were harvested and assayed by ELISA for IL-18 (b) and TNF (c). (d) Sorted populations were cytocentrifuged and examined by microscopy after May-Grünwald Giemsa stain. Bar, $10 \mu \mathrm{m}$. All data are representative of two independent experiments; error bars represent SEM of two technical replicates of two biological duplicates. ${ }^{* *}, \mathrm{P}<0.01 ;{ }^{* * *}, \mathrm{P}<0.001$ by unpaired $t$ test. reconstitution (Fig. 1 d). This was not significantly delayed when Wdr1 mutant BM was transplanted into an IL-18deficient host $\left(W d r 1^{r d / r d} \rightarrow I L-18^{-/-}\right)$. In contrast, wild-type mice reconstituted with Wdr1 mutant BM lacking IL-18 $\left(W d r 1^{r d / r d} I L-18^{-/-} \rightarrow\right.$ WT) developed disease with median onset at $46 \mathrm{~d}$ (Fig. $1 \mathrm{~d}$ ). Interestingly, genetic deletion of IL-18 from either the hematopoietic or nonhematopoietic compartment led to reduced serum IL-18 levels when compared with wild-type recipients of $W d r 1$ mutant $\mathrm{BM}\left(W d r r^{1 d / r d} \rightarrow\right.$ WT; Fig. 1 e). Collectively, these data indicate that pathogenic IL-18 is derived from the hematopoietic compartment of $W d r 1^{r d / r d}$ mice and that this is likely to act locally because decreased circulating IL-18 in $I L-18^{-/-}$recipients did not protect against $W d r 1^{r d / r d}$-mediated disease.

\section{Wdr ${ }^{r d / r d}$ M-CSF-derived cells secrete increased IL-18 in response to LPS}

In addition to the massive infiltration of neutrophils, F4/80 macrophages were found in the inflammatory lesions of the $W d r 1^{r d / r d}$ ears (Kile et al., 2007). To study inflammasome function in macrophages, we derived macrophages in M-CSF for $7 \mathrm{~d}$ - the standard technique for generation of macrophages ex vivo. We measured LPS-induced IL-18 secretion from wild-type and $W d r 1^{r d r d}$ day 7 BMDMs but, surprisingly, found no difference (Fig. 2 a). We also tested BM-derived DCs (cultured in GM-CSF) but found no difference in IL-18 secretion in response to LPS. We also generated $W d r 1^{\text {rd rd }} C D 11 c^{-}$ DTR-GFP BM chimeric mice, in which DCs were depleted by injection of diphtheria toxin (DT), that were not protected from disease (unpublished data).

It has been shown that IL-1 $\beta$ and IL-18 can be secreted by human monocytic THP-1 cells or inflammatory diseaseassociated monocytes in response to LPS (Chae et al., 2003; Seshadri et al., 2007; Netea et al., 2009). F4/80+ CD11b ${ }^{\text {int }}$ CD115(M-CSFR $)^{+}$monocytes can be found during culture of BM with M-CSF ex vivo, before the cells terminally differentiate into macrophages. To examine IL-18 secretion from monocytes, BM was cultured in M-CSF for between 1 and $7 \mathrm{~d}$, and cells were stimulated with LPS. IL-18 production was increased in response to LPS from Wdr1 mutant BM cells when cultured with M-CSF, peaking between 3 and $5 \mathrm{~d}$ of culture (Fig. 2 a). In contrast, TNF secretion was not elevated between wild-type and Wdr1 mutant cells at all time points (Fig. 2 b). This result led us to further analyze the cell populations in 

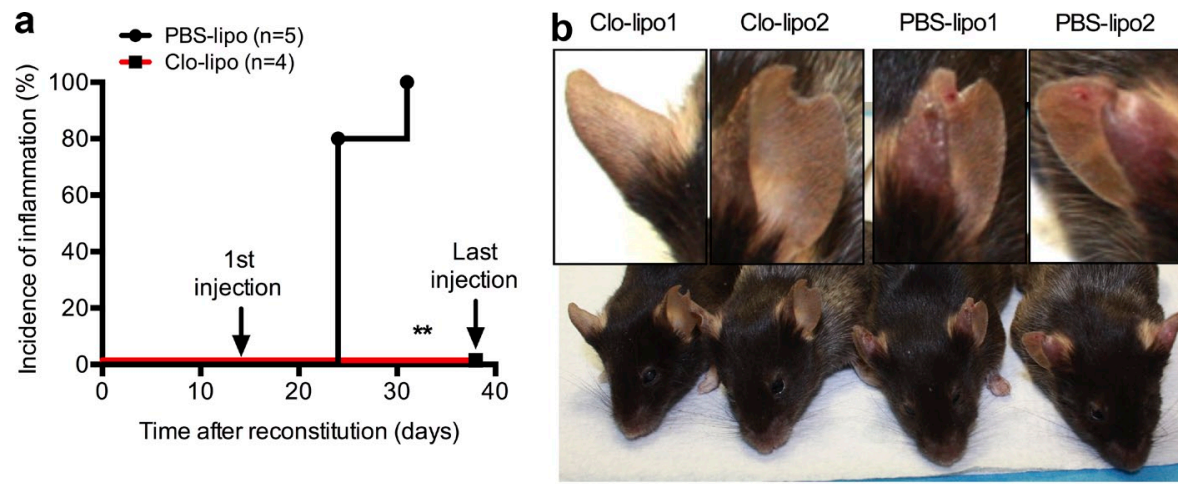

C

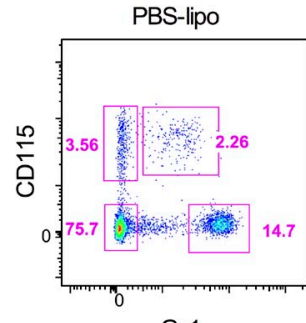

Gr1

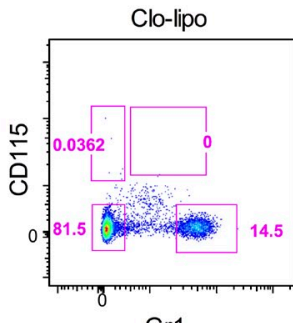

$\mathrm{Gr} 1$

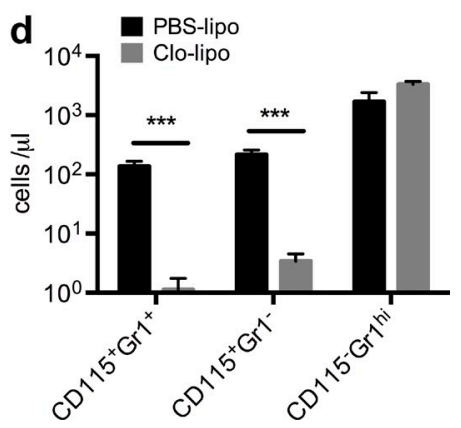

Figure 4. Clodronate liposome depletion of circulating monocytes prevents $W d r 1^{r d / r d}$ autoinflammatory disease. Lethally irradiated chimeric mice containing Wdr $r^{r d / r d}$ BM were injected intravenously with clodronate liposomes (Clo-lipo) or PBS liposomes (PBSlipo) twice per week starting from 2 wk after BM reconstitution. (a) Incidence of inflammation from chimeric mice after BM reconstitution. (b) After eight injections of liposomes, two representative mice from each group were photographed, and an ear from each mouse is highlighted. (c and d) $24 \mathrm{~h}$ after the fourth injection of liposomes, peripheral blood leukocytes were analyzed by flow cytometry as indicated by pink boxes (c) and quantified as $\mathrm{CD} 115^{+} \mathrm{Gr} 1^{-}$resident monocytes,

$\mathrm{CD} 115^{+} \mathrm{Gr} 1^{+}$inflammatory monocytes, and CD115- $\mathrm{Gr} 1^{\text {hi }}$ neutrophils (d). Error bars represent means \pm SEM $(n=5) .{ }^{*}, P<0.01$ by Gehan-Breslow-Wilcoxon test; ${ }^{* * *}, P<0.001$

by unpaired $t$ test. All data are representative of two independent experiments. day 3-5 BMDMs versus day 7 BMDMs. In day 7 BMDMs, $>98 \%$ of cells displayed high and homogenous CD11b expression $\left(\mathrm{CD} 11 \mathrm{~b}^{\text {hi }}\right.$ ), whereas in day 3-5 BMDMs, $\sim 40 \%$ (day 3) and 15\% (day 5) of cells showed intermediate CD11b expression (CD11bint) and were distinct from CD11b ${ }^{\text {hi }}$ cells (Fig. 2 c). To define the cell populations associated with IL-18 secretion in day 3-5 BMDMs, CD $11 b^{\text {hi }}$ and CD11bint from day 4 BMDMs were sorted by flow cytometry and cultured with LPS for $48 \mathrm{~h}$ to measure IL-18 secretion by ELISA. In populations of day 4 BMDMs, mutant CD $11 b^{\text {int }}$ cells secreted 2.5-fold more IL-18 than equivalent wild-type cells, whereas IL-18 secretion from CD $11 b^{\text {hi }}$ cells was similar between wild-type and Wdr1 mutant day 4 BMDMs (Fig. 2 d). Therefore, defects in $\mathrm{Wdr} 1$ function are driving IL-18 production in $\mathrm{F} 4 / 80^{+} \mathrm{CD} 11 \mathrm{~b}^{\text {int }} \mathrm{CD} 115^{+}$monocytes but not $\mathrm{F} 4 / 80^{+}$ CD $11 b^{\text {hi }} \mathrm{CD} 115^{+}$macrophages.

\section{Increased IL-18 production from Wdr1 mutant F4/80+CD11 $\mathrm{b}^{\text {int }} \mathrm{CD} 115^{+}$monocytes}

To delineate specific populations in day 3-5 BMDMs with increased IL-18 production, four distinct populations of CD $11 b^{\text {int/low }}$ cells were sorted: $\mathrm{CD} 115^{+} \mathrm{Gr}^{-}$(resident monocytes), $\mathrm{CD}_{115^{+}} \mathrm{Gr}^{+}$(inflammatory monocytes), $\mathrm{CD} 115^{-} \mathrm{Gr}^{+}$ (neutrophils), and CD115 ${ }^{-}$Gr1 ${ }^{-}$cells (Fig. 3 a). An IL-18 ELISA from culture supernatant revealed that the two CD $11 b^{\text {int/low }}$ $\mathrm{CD} 115^{+}$populations were the principal cell types secreting IL-18 in day 4 Wdr1 mutant BMDMs; immunophenotypically, these were resident $\left(\mathrm{CD} 115^{+} \mathrm{Gr} 1^{-}\right)$and inflammatory $\left(\mathrm{CD} 115^{+} \mathrm{Gr}^{+}\right.$) monocytes (Fig. 3 b). In contrast, TNF secretion in response to LPS was normal in Wdr1 mutant cells (Fig. 3 c). The cellular morphology of CD $11 b^{\text {int } / \text { low } C D 115^{+}}$ cells was consistent with monocytes and not mature macrophages (Fig. 3 d). The Wdr1 mutant monocytes were not morphologically distinct from wild type; however, Wdr1 mutant neutrophils (CD115 ${ }^{-} \mathrm{Gr}^{+}$) displayed prominent nuclear herniation (Fig. 3 d).

\section{Clodronate liposome depletion of circulating monocytes prevents $W d r 1^{r d / r d}$ autoinflammatory disease}

To establish the role of monocytes in disease pathogenesis in vivo, we used clodronate liposomes (van Rooijen and van Nieuwmegen, 1984). Clodronate or PBS liposomes were repeatedly injected intravenously twice per week starting 2 wk after mice were reconstituted with $W d r 1^{r d / r d}$ BM. Caspase-1deficient recipients were used to reduce IL-18 production from nonhematopoietic cells. The PBS liposome control cohort developed inflammation 3-4 wk after BM transplantation, whereas the group that received clodronate liposomes was protected from inflammation until the termination of liposome injection 6 wk after BM reconstitution (Fig. 4 a). Unexpectedly, we found that serum IL-18 levels are increased upon injection of clodronate liposomes, even in mice reconstituted with wild-type BM (unpublished data). The profound effect of clodronate liposomes indicated that the cells depleted by clodronate were critical to initiate disease (Fig. 4 b). Flow cytometric analysis of peripheral blood demonstrated that $>99 \%$ of both $\mathrm{CD} 115^{+} \mathrm{Gr} 1^{-}$resident monocytes and $\mathrm{CD}_{115^{+}} \mathrm{Gr}^{+}$inflammatory monocytes were depleted by clodronate administration, whereas $\mathrm{CD} 115^{-} \mathrm{Gr} 1^{\text {hi }}$ neutrophils were not affected (Fig. 4, c and d). As we have previously excluded a dominant role for mature macrophages, DCs, neutrophils, and lymphocytes in IL-18 production and inflammatory disease, 

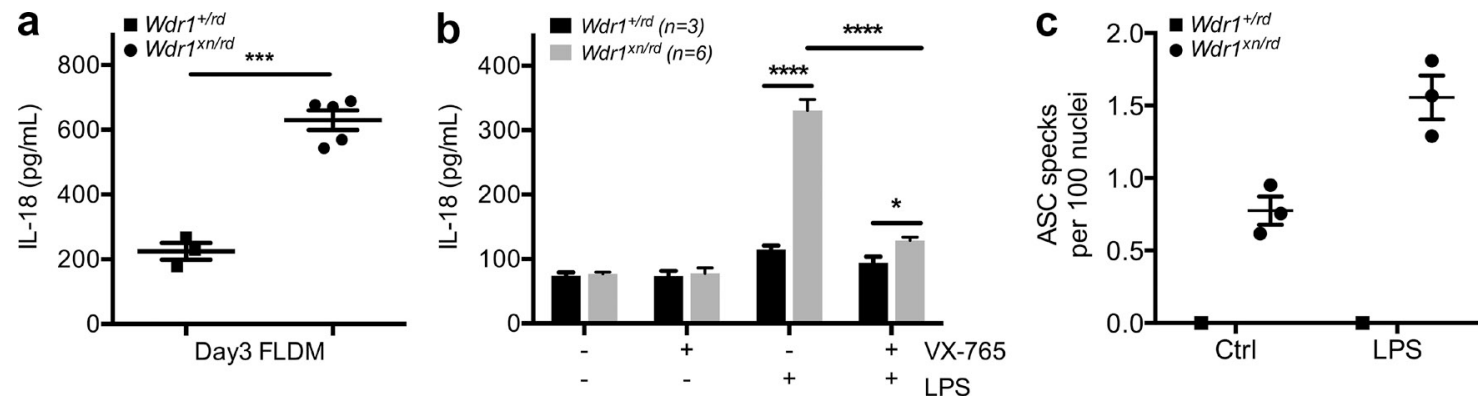

Figure 5. Caspase-1 and ASC activation in Wdr1 mutant monocytes. E14.5 fetal livers from Wdr1+/rd or Wdr $7 \times n / r d$ embryos were cultured in L929 cell-conditioned medium for $3 \mathrm{~d}$. (a and b) $10^{5}$ FLDMs from day 3 cultures were incubated with $1 \mu \mathrm{g} / \mathrm{ml}$ LPS (a) or treated with LPS \pm VX-765 (b). $48 \mathrm{~h}$ after stimulation, culture supernatants were harvested and assayed by ELISA for IL-18. (c) $24 \mathrm{~h}$ after stimulation, cells were fixed and permeabilized, with intracellular ASC specks stained and then imaged by confocal microscopy. All data are representative of two to four independent experiments; error bars represent means \pm SEM $(n=3-6)$. ${ }^{*}, \mathrm{P}<0.05 ;{ }^{* * *}, \mathrm{P}<0.001 ;{ }^{* * *}, \mathrm{P}<0.0001$ by unpaired $t$ test.

these data suggest that local production of IL-18 by infiltrating monocytes is a key initiating event in disease pathology in $W d r 1^{r d / r d}$ mice.

Polymerized actin triggers ASC specks, caspase- 1 activation, and IL-18 secretion in Wdr1 mutant monocytes

To study this system in more detail, we were interested to examine monocytes with a more severe defect in $\mathrm{Wdr} 1$ function. It was previously shown that the $r d$ allele of $\mathrm{Wdr} 1$ is hypomorphic and not a complete loss of function, whereas Wdr1 deficiency caused by a gene-trap allele $\left(W d r 1^{x n / x n}\right)$ causes embryonic lethality because of developmental abnormalities (Kile et al., 2007). The compound heterozygote $\left(W d r 1^{x n / r d}\right)$ exhibits an intermediate phenotype, and mice die at birth from an unknown etiology (unpublished data). In agreement with a more severe loss of Wdr1 function, $W d r 1^{\text {xn/rd }}$ embryonic day 14.5 (E14.5) fetal liver-derived monocytes (FLDMs) secreted very high levels of IL-18 in response to LPS compared with healthy $W d r 1^{+/ r d}$ controls (Fig. 5 a). To establish whether this is dependent on the activity of caspase-1, we used the caspase-1 inhibitor VX-765. LPS-treated $W d r^{x n / r d}$ day 3 FLDMs showed reduced IL-18 production in the presence of VX-765 (Fig. 5 b). Furthermore, confocal analysis of the inflammasome adaptor ASC revealed spontaneous specks that were increased by treatment with LPS (Fig. 5 c).

Next, we used latrunculin-b and colchicine to determine the role of the actin cytoskeleton in caspase- 1 activation and IL-18 secretion. Latrunculins are marine toxins that disrupt microfilament organization in cultured cells and can disrupt actin polymerization (Spector et al., 1983, 1989). Colchicine is another cytoskeletal drug that functions to inhibit microtubule polymerization by binding to tubulin, and it can prevent inflammasome activation in gout and FMF (Özkaya and Yalçinkaya, 2003). We measured the effects of latrunculin- $b$ and colchicine on LPS-induced caspase- 1 activation and IL-18 secretion in both $W d r 1^{r d / r d}$ and $W d r 1^{x n / r d}$ monocytes by Western blotting and ELISA (Fig. 6, a-c). Caspase-1 activation was not detected in either wild-type or mutant monocytes in the absence of LPS. In the presence of latrunculin-b or colchicine, LPS-induced caspase-1 activation and IL-18 production were reduced, suggesting a direct role of a dysfunctional actin cytoskeleton during inflammasome activation in Wdr1 mutant cells (Fig. 6, a-c). Cleavage and activation of caspase- 1 by nigericin was included as a positive control and was found to be normal in Wdr1 mutant monocytes.

Finally, we used inhibitors of the Rho/Rho-associated protein kinase pathway to promote actin depolymerization, specifically the Arp2/3 inhibitor CK-666 and the Rho-associated protein kinase inhibitor Y27632. IL-18 production by $W d r 1^{\text {xn } / r d}$ monocytes was significantly decreased when these inhibitors were present (Fig. 6 d). Phalloidin staining of actin confirmed that all inhibitors worked as expected, to decrease filamentous actin (Fig. 6 e). This provides further evidence that polymerized actin, or a byproduct thereof, activates the inflammasome and triggers IL-18 production. In summary, these small-molecule inhibitors show that the DAMP that activates the inflammasome because of loss of $\mathrm{Wdr} 1$ is in the actin polymerization pathway, is specific to monocytes, and causes IL18-dependent pathology in vivo.

\section{$W d r 1^{r d / r d}$ autoinflammatory disease is controlled by the pyrin inflammasome}

To determine whether pathogenic IL-18 in the Wdr1 mutant mice is mediated by caspase-1, we generated caspase-1deficient $W d r 1^{r d / r d}$ mice. Relative to their $W d r 1^{\text {rddrd }}$ counterparts, serum IL-18 levels were profoundly reduced in $W d r 1^{\text {rd }}$ rd Casp $1^{-1-}$ animals (Fig. 7 a). Consistent with the central role of IL-18 in this disease, the onset of inflammation was significantly delayed in $W d r 1^{r d / r d}$ Casp $1^{-/-}$mice (Fig. 7 b). It has been noted that caspase-1-deficient mice are also deficient for caspase-11 (Kayagaki et al., 2011) and that caspase11 can interact with Wdr1 (Li et al., 2007). Formally testing Casp $11^{-1-}$-deficient mice, however, revealed no protection from disease (Fig. 7 b). These data indicated that caspase-1 plays a key role in the development of autoinflammatory disease and prompted us to investigate the upstream innate immune 


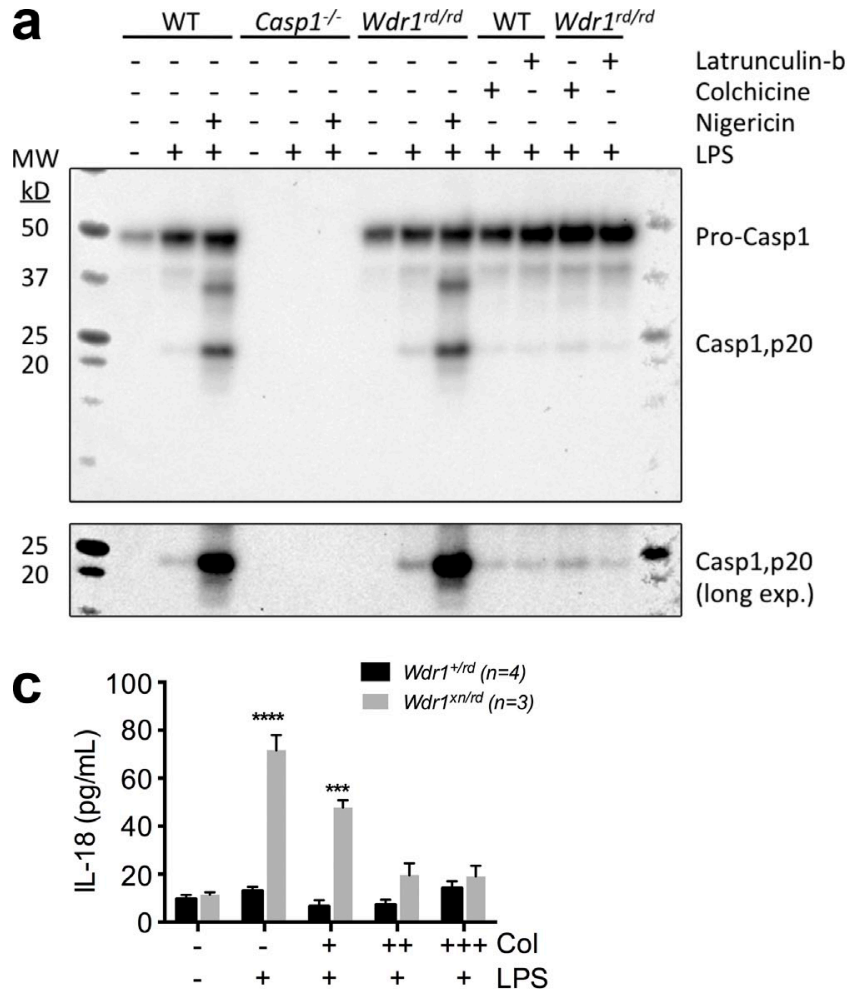

e
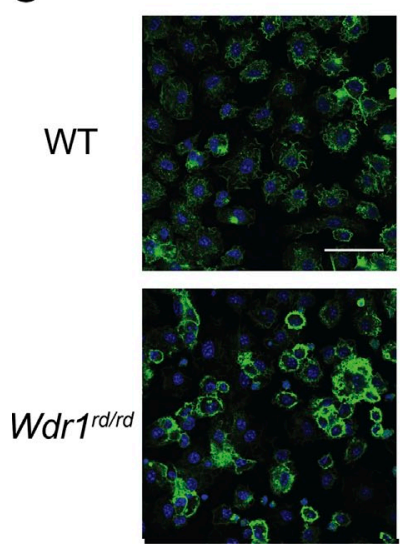

CK-666
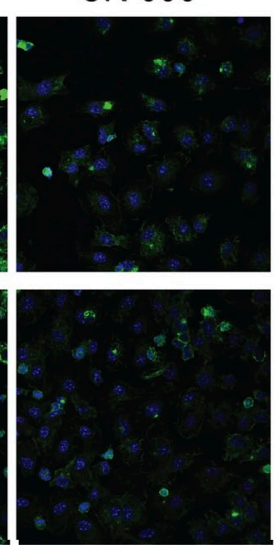

Colchicine

Nigericin

LPS

Pro-Casp1

Casp1,p20

Y27362
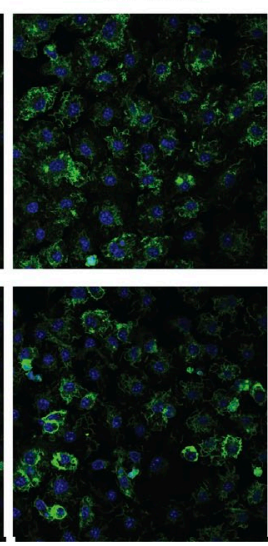
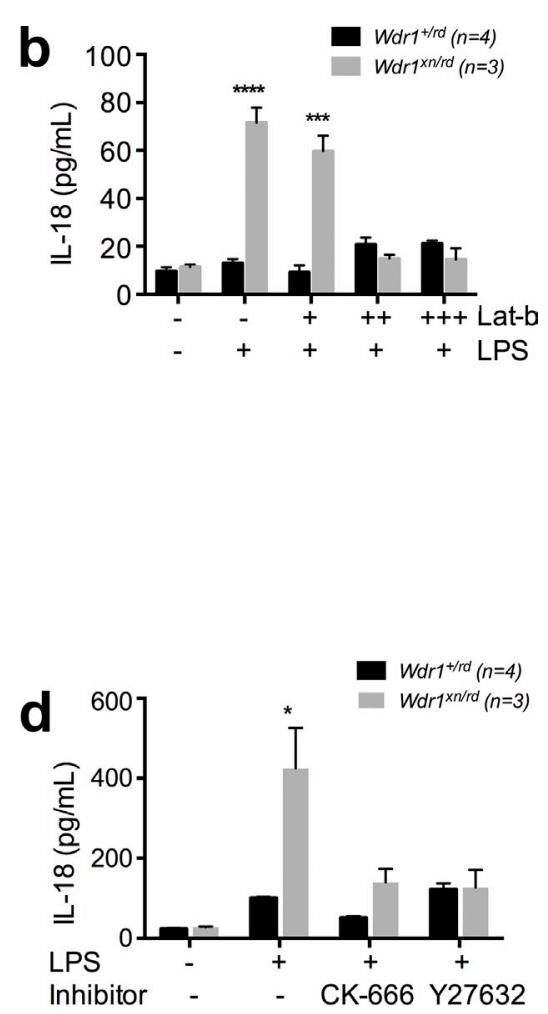

Inhibito

Lat-b

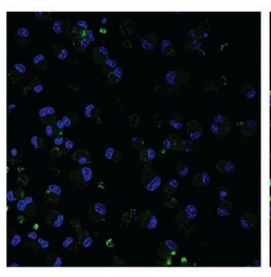

Col

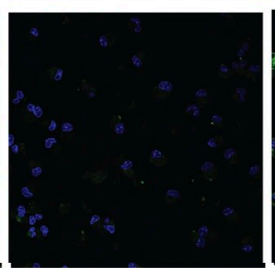

Figure 6. Inhibition of actin polymerization prevents caspase-1 activation and IL-18 secretion from Wdr1 mutant monocytes. (a) Western blot analysis of caspase- 1 in the supernatant from wild-type (WT), caspase- $1^{-/-}$(Casp $1^{-/-}$), and Wdr rddrd $^{\text {day }} 4$ BMDM culture. A long exposure (long exp.) is also presented for the cleaved caspase-1 (p20) band. Cells were left untreated, stimulated with $1 \mu \mathrm{g} / \mathrm{ml}$ LPS, or incubated with $10 \mu \mathrm{M}$ nigericin after LPS priming. Additionally, wild-type and Wdr $r^{\text {rd/rd }}$ cells were pretreated with $1 \mu \mathrm{M}$ latrunculin-b or $1 \mu \mathrm{M}$ colchicine for 30 min before LPS stimulation. MW, molecular weight. (b-d) Day 4 FLDMs from Wdr1+/rd or Wdr 1xn/rd were left untreated or treated with LPS plus an increasing dose of latrunculin-b (Lat-b; b) or colchicine (Col; c) for $16 \mathrm{~h}$, or with LPS in the presence of $100 \mu \mathrm{M}$ CK-666 or $50 \mu \mathrm{M}$ Y 27632 for $48 \mathrm{~h}$ (d). Secreted IL-18 in the culture supernatants was measured by ELISA. (e) Day 3 wild-type or Wdr 1rd/rd BMDMs were stimulated with LPS for $24 \mathrm{~h}$ in the presence of the inhibitors used previously and then were fixed and stained with phalloidin to detect filamentous actin. Green, phalloidin-FITC; blue, nuclei-DAPI. Bar, $50 \mu \mathrm{m}$. All data are representative of two to four independent experiments; error bars represent means $\pm \operatorname{SEM}(n=3-4) .{ }^{*}, \mathrm{P}<0.05 ;{ }^{* * *}, \mathrm{P}<0.001$; ${ }^{* * * *}, \mathrm{P}<0.0001$ by unpaired $t$ test.

receptor that may detect perturbed actin polymerization in $W d r 1^{r d / r d}$ mice.

Several innate immune receptors engage with caspase-1 to form multiprotein inflammasome complexes. Many of these require the adaptor molecule ASC; however, others, such as
NLRP1, do not (Masters et al., 2012). Deletion of NLRP1 did not protect $\mathrm{Wdr} 1$ mutant mice, whereas the deletion of ASC did delay the onset of inflammatory disease (Fig. 7 c), showing that innate immune receptor activation requires the downstream adaptor protein ASC. We crossed $W d r 1^{r d / r d}$ mice 
a

$\triangle$ WT

- $W d r^{r d / r d}$

- Wdr1 ${ }^{\text {rd/rd }}$ Casp1\%
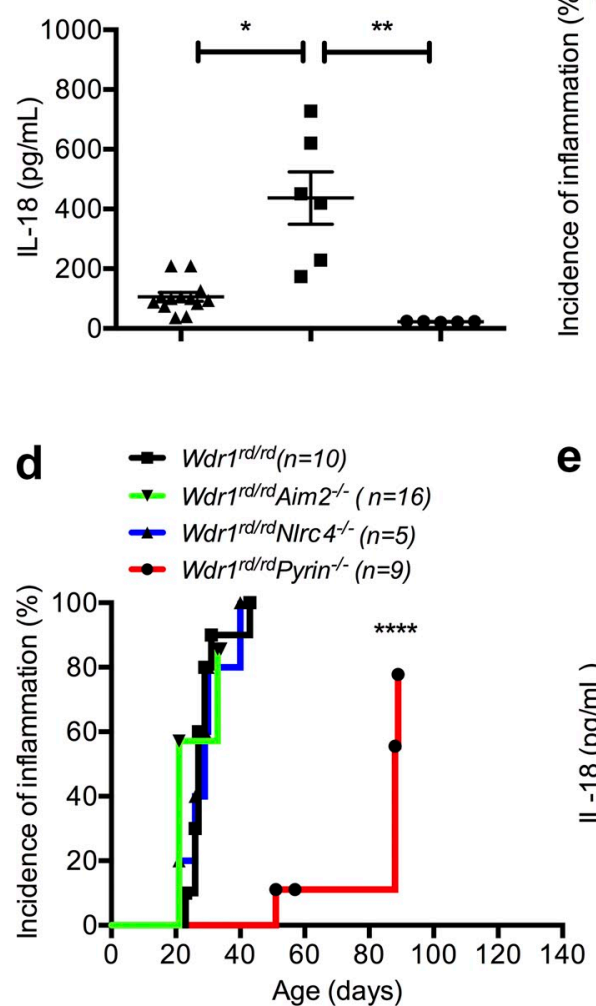
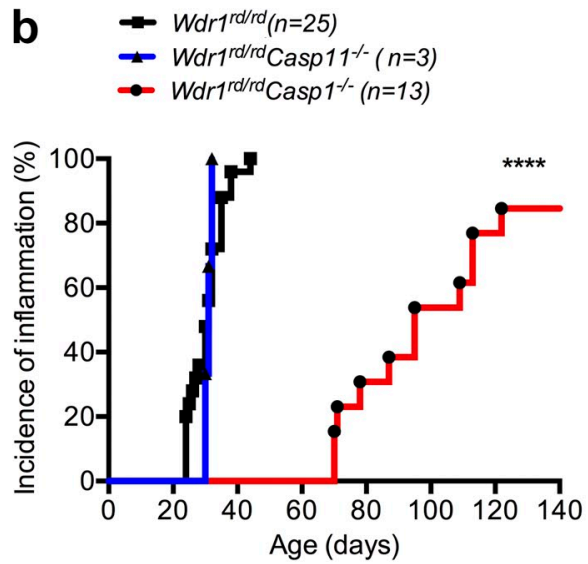

e $\quad \Delta \mathrm{WT}$

- Pyrin ${ }^{-1-}$

- Wdr1rd/rd

- Wdr1 ${ }^{\text {rdrdrdPyrin }}{ }^{--}$

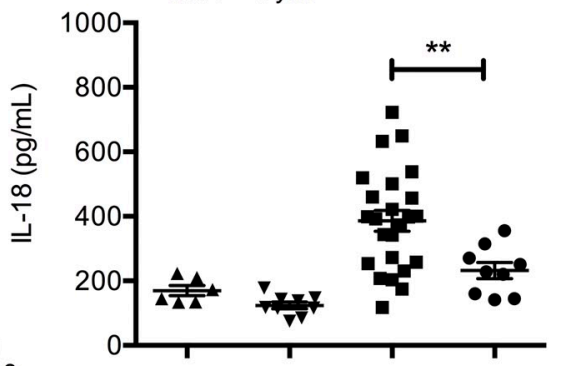

C $\quad \rightarrow W d r 1^{r d / r d}(n=5)$

- Wdr1rd/rd NIrp 3-- $(n=6)$

- Wdr1rdird Nirp1\% $(n=10)$

$\rightarrow W d r 1^{r d / r d} A s c^{--}(n=9)$

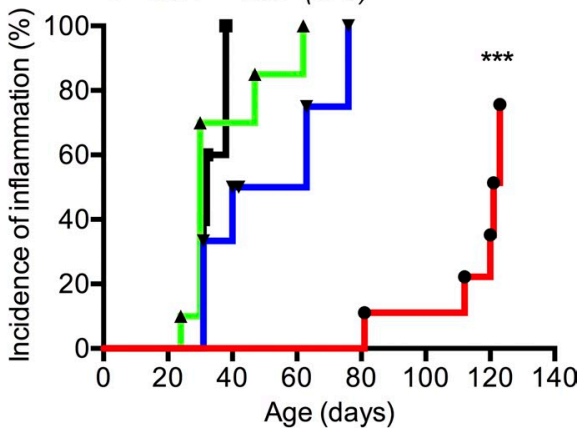

$f \quad-W d r 1^{r d / r d}(n=7)$

- Wdr1 ${ }^{\text {rddrd }}$ (germ-free, $n=7$ )

$\rightarrow W d r 1^{r d / r d} / L-18^{-/-}(n=13)$

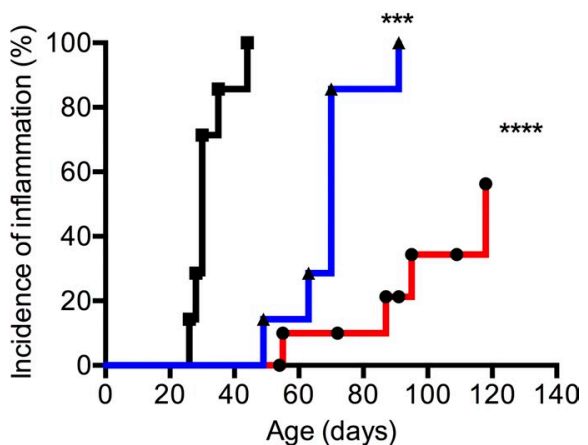

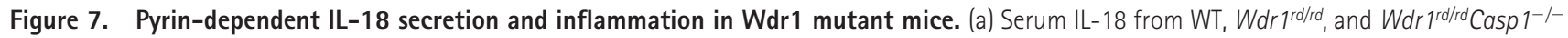

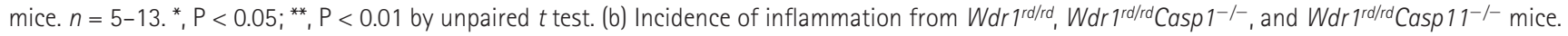

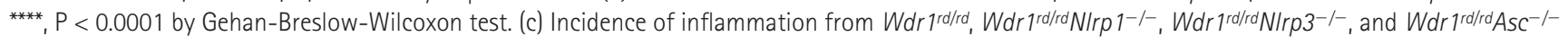

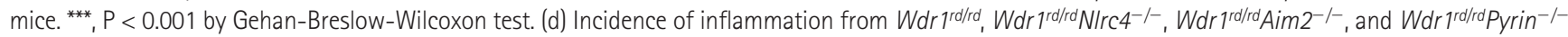

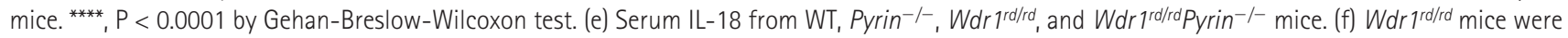
rederived in a gnotobiotic facility to establish any potential role for commensal microbes in the inflammatory pathology caused by a loss of Wdr. This is compared with conventionally housed Wdr $r^{r d / r d}$ and Wdr $7^{r d / r d} / L-18^{-/-}$mice. ${ }^{* * *}, \mathrm{P}<0.001 ;{ }^{* * *}, \mathrm{P}<0.0001$ by Gehan-Breslow-Wilcoxon test. Except for disease incidence, data are representative of two to four independent experiments. $n=5-25$. Error bars represent means \pm SEM.

to different ASC-dependent, inflammasome-deficient mice. NLRP3 was an excellent candidate, as it can be activated in response to different danger signals; however, a deficiency of NLRP3 afforded no protection from disease (Fig. 7 d). Given the nuclear herniation observed in $W d r 1^{r d / r d}$ neutrophils, it was possible that DNA was being sensed by the AIM2 inflammasome; however, a deficiency in AIM2 also afforded no protection from disease (Fig. 7 d). Recently, it has been shown that NLRC4 is activated in response to changes in actin polymerization during Salmonella enterica Typhimurium infection (Man et al., 2014), but NLRC4 deficiency played no obvious role in this model of sterile inflammation (Fig. 7 d). Finally, we tested the pyrin (Mefv) inflammasome, which is reported to directly interact with actin (Mansfield et al., 2001; Richards et al., 2001; Waite et al., 2009). We found that Wdr1 $1^{\text {rd/rd }}$ Pyrin ${ }^{-/-}$mice were protected from disease compared with $W d r 1^{\text {rd/rd }}$ littermate controls (Fig. 7 d) and that serum IL-18 was no longer elevated (Fig. 7 e). Although the Wdr $1^{\text {rd/rd }}$ Pyrin $^{-/-}$cross was performed in a separate facility (National Institutes of Health, Bethesda, MD) than the other inflammasomes (The Walter and Eliza Hall Institute of Medical Research, Parkville, Australia), a role for different microbiota is unlikely because this disease proceeds in a gnotobiotic facility (Fig. 7 f).

Recently, a trigger for the pyrin inflammasome has been proposed, downstream of RhoGTPase modification by bacterial effectors such as Clostridium difficile Toxin B (TcdB; Xu et al., 2014). We therefore tested this recombinant toxin on $W d r 1^{r d / r d}$ monocytes and observed a significant increase in IL-18 production compared with wild type (Fig. 8 a). IL-18 production after stimulation of the NLRP3 inflammasome with nigericin was unaltered (Fig. 8 a). Notably, IL-1 $\beta$ production was negligible unless first primed with LPS (Fig. 8 b). This suggests that the IL-18 specificity in this disease may 

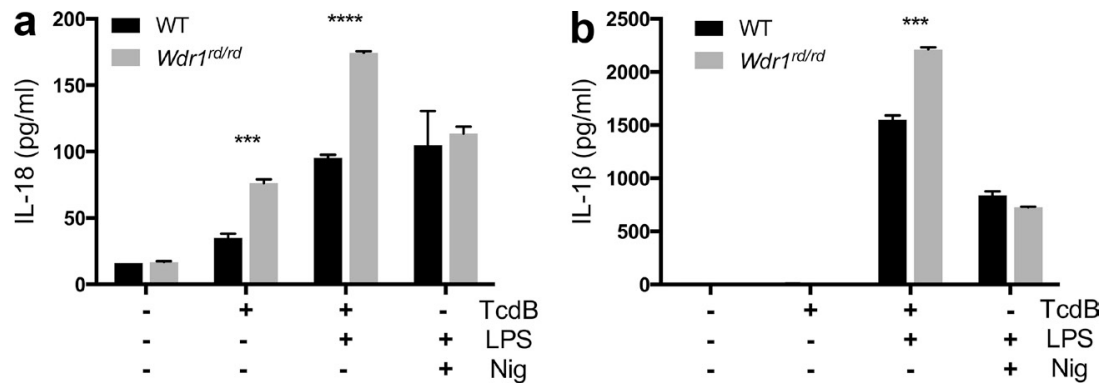

Figure 8. Enhanced IL-18 production from Wdr1 mutant monocytes in response to TcdB. Wild-type and Wdr $7^{r d / r d}$ day 3 BMDMs were left untreated or stimulated with $20 \mathrm{ng} / \mathrm{ml}$ TcdB for $3 \mathrm{~h}$ or $10 \mu \mathrm{M}$ nigericin (Nig) for $1 \mathrm{~h}$ with or without $1 \mu \mathrm{g} / \mathrm{ml}$ LPS. (a and b) Secreted IL-18 (a) or secreted IL-1 $\beta$ (b) in the culture supernatants was measured by ELISA. All data are representative of two independent experiments; error bars represent means $\pm \operatorname{SEM}(n=3)$. ${ }^{* * *}, \mathrm{P}<0.001 ;{ }^{* * * *}, \mathrm{P}<0.0001$ by unpaired $t$ test. arise because it is a sterile inflammatory condition without significant IL-1 $\beta$ priming in monocytes. In total, these data indicate that the pyrin inflammasome, including ASC and caspase-1, alerts the host cell to perturbations in the process of actin depolymerization.

\section{DISCUSSION}

Pyrin was the first protein implicated in autoinflammatory disease due to mutations that activate the innate immune system in FMF (The International FMF Consortium, 1997). Subsequent work showed that this protein formed an inflammasome complex for the activation of IL-1 $\beta$ and IL-18 and that it is also an actin-binding protein (Mansfield et al., 2001; Richards et al., 2001; Waite et al., 2009). We now show that a lack of actin depolymerization triggers the pyrin inflammasome in vivo, using a mouse model of autoinflammatory disease. However, deletion of pyrin inflammasome components did not totally rescue the disease, suggesting that other inflammatory processes are also contributing to the phenotype. Crosses to mice lacking Clec9a, or other innate immune receptors that may recognize perturbations in actin polymerization, are currently under way.

Unlike all known hereditary autoinflammatory disorders, the disease described here is ameliorated by genetic deletion of IL-18, whereas genetic removal of IL-1 $\beta$ has no discernible effect on disease initiation. Given that these two proinflammatory cytokines are generated by the same enzymatic reaction, this observation is quite unique and raises the question about how this selectivity may arise. Our data suggest that this is because of cell type, with a prominent role for the monocyte in disease development. Baseline levels of IL-18 in monocytes are higher than IL-1 $\beta$, which requires priming through a TLR for maximal induction, as shown in Fig. 8. The pattern of expression of pyrin may also explain the importance of the monocyte, where it is elevated compared with macrophages, or other hematopoietic cells, with the exception of some DCs (Seshadri et al., 2007). Additionally, monocytes may generate increased amounts of incompletely depolymerized, severed actin filaments and/or accumulate inflammatory DAMPs downstream of these events. This also highlights that the biochemical entity engaging pyrin has yet to be properly defined. In contrast to our findings, $\mathrm{Xu}$ et al. (2014) document that pyrin is triggered downstream of bacterial effectors that target RhoGTPases, which were predicted to decrease actin polymerization. As these processes are so dynamic and tightly regulated at a subcellular level, these data are not in conflict with ours but do emphasize the complexity by which actin and pyrin are regulated. It is tempting to speculate that the trigger is some modified form of actin given that pyrin binds to, and colocalizes with, polymerizing actin (Mansfield et al., 2001; Richards et al., 2001; Waite et al., 2009). However, further work is required to investigate this interaction.

Our results highlight that the pyrin inflammasome is a potent platform for IL-18 production. This has direct implications for diseases where pyrin is activated, such as in FMF, or as a result of infections such as C. difficile or Burkholderia cenocepacia, where effectors target RhoGTPases. Indeed, it is known that IL-18 is elevated in FMF (Haznedaroglu et al., 2005), and although therapy blocking IL-1 was found to be beneficial, the effect of blocking IL-18 may be more robust and is worth exploring in preclinical models. However, for infection with $C$. difficile or B. cenocepacia, IL-18 may actually be beneficial in restoring normal homeostasis (CeballosOlvera et al., 2011; Elinav et al., 2011). IL-18 may also be associated with inflammatory diseases caused by other bacterial effectors that target RhoGTPases, which are found in a broad range of mucosal pathogens (Müller et al., 2010), or microbes that hijack host actin cytoskeletal machinery, such as Listeria or Shigella (Gouin et al., 2005).

In summary, our data show that innate immune surveillance of actin dynamics is not confined to settings of infection but also alerts the host cell to changes in actin depolymerization and contributes to autoinflammatory disease that is dependent on IL-18, not IL-1ß.

\section{MATERIALS AND METHODS}

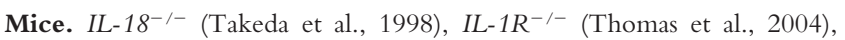
IFN $\boldsymbol{\gamma}^{-/-}$(Dalton et al., 1993), TNFR ${ }^{-/-}$(Pfeffer et al., 1993), G-CSF-1-

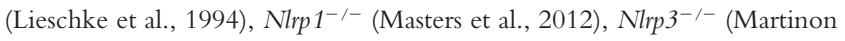
et al., 2006), $\mathrm{Asc}^{-/-}$(Mariathasan et al., 2004), Casp-1-/- (Li et al., 1995), Aim2 ${ }^{-/-}$(Hornung et al., 2009), Pyrin ${ }^{-1-}$ (Chae et al., 2003), CD11c-DTR (Jung et al., 2002), and Nlrc $4^{-/-}$(Franchi et al., 2006) mouse strains were crossed with $W d r 1^{r d / r d}$ (Kile et al., 2007) mice. All mice were backcrossed at least 10 generations to $\mathrm{C} 57 \mathrm{BL} / 6$, and littermates were used as controls. Lesions were assessed by independent observers three times per week and defined as redness, swelling, lumps, scabs, or lesions and were marked for the first day when inflammation appeared on the ears or tail.

All animal experiments complied with the regulatory standards of, and were approved by, The Walter and Eliza Hall Institute Animal Ethics Committee or National Institutes of Health Office of Laboratory Animal Welfare. 
BM chimeras. For hematopoietic reconstitution experiments, 6-8-wk-old congenic C57BL/6.SJL (Ptprc ${ }^{a}$ Pep $3^{b}$ [Ly5.1]) mice were reconstituted with $5 \times 10^{6}$ Ptprc $^{b}$ Pep3 $3^{a}$ (Ly5.2) BM cells from wild-type, $I L-18^{-1-}, W d r 1^{r d / r d}$, or $W d r 1^{r d r d} I L-18^{-/-}$mice. For clodronate liposome experiments, Ly5.1 mice or Casp $1^{-1-}$ mice were reconstituted with $5 \times 10^{6}$ Ly5.2-expressing $W d r 1^{r d / r d}$ BM cells. Recipient mice received two 5.5-Gy doses of irradiation given $3 \mathrm{~h}$ apart.

Isolation of BMDMs or FLDMs. BM cells were collected from the femur and tibia of mice. Fetal liver cells were harvested from E14.5 mouse embryos. For isolation of day 1-7 BMDMs on the same day (to ensure consistency), aliquots of BM cells from two mice were frozen in 90\% FCS and $10 \%$ DMSO and subsequently cultured in DMEM containing 10\% FCS, $10 \mathrm{mM}$ Hepes, $1 \mathrm{mM}$ pyruvate, $10 \mathrm{mM} \mathrm{L-glutamine}$, and 10\% L929 cellconditioned medium on bacteriological Petri dishes at $37^{\circ} \mathrm{C}$ and $10 \% \mathrm{CO}_{2}$. For day 4 BMDMs or day 3 or 4 FLDMs, BM cells or fetal liver cells were cultured on the same day of collection from mice. For collection of entire cell populations on the day of experiments, nonadherent cells were harvested by pipetting, and adherent cells were treated with ice-cold PBS with $2 \mathrm{mM}$ EDTA and collected by pipetting up and down. After centrifugation at $400 \mathrm{~g}$ for $5 \mathrm{~min}$ at $4^{\circ} \mathrm{C}$, cells were resuspended in DMEM containing 10\% FCS and counted manually. For cytokine ELISA, $10^{5}$ cells were seeded in a 96well tissue culture plate and 30 min later were stimulated with $1 \mu \mathrm{g} / \mathrm{ml} \mathrm{LPS}$ for $48 \mathrm{~h}, 20 \mathrm{ng} / \mathrm{ml}$ LPS + TcdB (Abcam) for $3 \mathrm{~h}$, or $10 \mu \mathrm{M}$ LPS + nigericin (Enzo Life Sciences) for $1 \mathrm{~h}$.

Cell sorting and flow cytometry. Entire cell populations of day 4 BMDMs were stained with a mix of monoclonal antibodies CD11b-Alexa 700, Gr-1APC (The Walter and Eliza Hall Institute Monoclonal Antibody Facility), and CD115-PE (BD) in $1 \mathrm{ml} \mathrm{FACS} \mathrm{buffer} \mathrm{(PBS,} \mathrm{2 \%} \mathrm{FCS,} \mathrm{and} 2 \mathrm{mM}$ EDTA) for $20 \mathrm{~min}$ on ice and sorted with a cell sorter (Aria W; BD). Flow cytometric analysis of hematopoietic cells was performed with a cell analyzer (LSRFortessa; BD), and data were analyzed and processed using FlowJo software. Sorted cells were cytocentrifuged at 1,000 rpm for $5 \mathrm{~min}$, stained using a May-Grünwald Giemsa solution, and inspected by light microscopy.

Cytokine ELISA and BioPlex. Serum cytokines and chemokines were measured by BioPlex (Bio-Rad Laboratories) according to the manufacturer's instructions. For cytokine ELISA, $5 \times 10^{4}$ (FACS sorted) or $10^{5}$ total cells were seeded in a 96-well tissue culture plate in technical duplicate or triplicate and, $30 \mathrm{~min}$ later, were stimulated with $1 \mu \mathrm{g} / \mathrm{ml}$ LPS (Enzo Life Sciences) for $48 \mathrm{~h}$. To measure cytokines from cell culture supernatants, BMDMs or FLDMs were cultured and stimulated in 96-well plates. Unless stated, culture supernatants were collected $48 \mathrm{~h}$ later as described in the figure legends, and ELISAs were performed for IL-1 $\beta$ and IL-18 (R\&D Systems) as described previously (Westwell-Roper et al., 2013) and for TNF (eBioscience) according to the manufacturer's instructions.

Clodronate liposome or DT injection. $200 \mu \mathrm{l}$ clodronate or PBS liposomes (http://www.ClodronateLiposomes.com) were administered intravenously into the $\mathrm{Wdr} 1$ mutant $\mathrm{BM}$-reconstituted Casp $1^{-/-}$recipient mice 2 wk after reconstitution and repeated twice per week (Monday and Friday) for $4 \mathrm{wk}$. For flow cytometric analysis of monocyte populations in the peripheral blood, mice were bled $24 \mathrm{~h}$ after the fourth injection of clodronate or PBS liposomes. To deplete DC populations before the onset of inflammation, $W d r r^{r d / r d} C D 11 c-D T R$-GFP BM chimeric mice were given i.p. injections of $5 \mathrm{ng} / \mathrm{g}$ DT (CSL) three times per week for 2-3 wk starting from $1 \mathrm{wk}$ after $\mathrm{BM}$ reconstitution. $24 \mathrm{~h}$ after final injection of DT, the depletion of DCs was confirmed by flow cytometric analysis of $\mathrm{GFP}^{+} \mathrm{CD} 11 \mathrm{c}$ populations.

Caspase-1 (p20) Western blot. To measure spontaneous or LPS-induced activation and secretion of caspase- 1 in supernatants of monocytes, day 4 BMderived cells $\left(2 \times 10^{6}\right)$ were seeded in a 12-well plate in $1 \mathrm{ml}$ of medium (DMEM containing 10\% FCS). Cells were then left untreated for $4 \mathrm{~h}$, washed with serum-free medium (DMEM), and incubated for $44 \mathrm{~h}$ or stimulated with $1 \mu \mathrm{g} / \mathrm{ml}$ LPS for $4 \mathrm{~h}$, washed with DMEM, and incubated with or without $10 \mu \mathrm{M}$ nigericin (Enzo Life Sciences) in DMEM for $44 \mathrm{~h}$. Additionally, wild-type and $W d r r^{\text {rd } r d}$ cells were pretreated with $1 \mu \mathrm{M}$ latrunculin-b (Enzo Life Sciences) or $1 \mu \mathrm{M}$ colchicine (Sigma-Aldrich) for $30 \mathrm{~min}$ before LPS priming for $4 \mathrm{~h}$, washed with DMEM, and incubated for $44 \mathrm{~h}$ with or without latrunculin-b or colchicine. Culture supernatants were then collected and enriched by methanol chloroform precipitation (Masters et al., 2010). Precipitates were boiled for 5 min with SDS sample buffer, resolved by SDS/PAGE, and transferred to polyvinylidene fluoride membranes. After blocking in PBS with $0.1 \%$ Tween 20 and 5\% skim milk for $1 \mathrm{~h}$, membranes were then probed overnight at $4^{\circ} \mathrm{C}$ with anti-caspase-1 (p20; AdipoGen).

Immunofluorescence for endogenous ASC specks or filamentous actin. Day 3 BMDMs were seeded onto RetroNectin-coated chamber slides (Takara Bio Inc.) and stimulated as described in figure legends. Cells were then fixed with $4 \%$ paraformaldehyde in PBS for $30 \mathrm{~min}$ and washed twice in PBS before blocking and permeabilization in blocking buffer (PBS, $10 \%$ FCS, and $0.5 \%$ Triton X-100) for $60 \mathrm{~min}$. Staining was then performed with primary antibodies ASC (1:500 N-15; Santa Cruz Biotechnology, Inc.) or phalloidin-FITC (1:400; Sigma-Aldrich) in blocking buffer overnight at $4^{\circ} \mathrm{C}$. Cells were washed three times with blocking buffer, and secondary antibody staining for ASC was performed with goat anti-rabbit Alexa 647 (1:1,000; Invitrogen) in blocking buffer for $60 \mathrm{~min}$ at room temperature (in the dark). Cells were washed twice with PBS before imaging. Images were acquired with a confocal microscope (LSM 780; Carl Zeiss) at room temperature using a $40 \times$ oil objective with Immersol $518 \mathrm{~F}$ (refractive index $n=$ 1.518; Carl Zeiss) and a 1.4 numerical aperture and were acquired with ZEN 2012 v8.1 software (Carl Zeiss). Image channels were merged and converted to TIFF using FIJI software.

Statistical analysis. Data are presented as means \pm SEM. Statistical significance was determined with the Student's $t$ test or ANOVA using Prism software (GraphPad Software Inc.) as described in the figure legends. Multiple comparisons were corrected using the Holm-Šidák method; inflammation incidence curves were compared by Gehan-Breslow-Wilcoxon test.

We thank S. Mifsud and J. Corbin for excellent technical assistance and E. Lanera, L. Scott, K. Scicluna, and R. Crawley for outstanding animal husbandry.

This work was supported by project grants (1008131 and 1043414), program grants (1016647 and 1037321), fellowships (to B.T. Kile, B.A. Croker, A.M. Lew, and S.L. Masters), a National Institutes of Health grant (1R56Al103352-01A1; to B.A. Croker), and an Independent Research Institutes Infrastructure Support Scheme grant (361646) from the National Health and Medical Research Council; fellowships from the Victorian Endowment for Science Knowledge and Innovation (to S.L. Masters), the Australian Research Council (to B.A. Croker and B.T. Kile), the Sylvia and Charles Viertel Charitable Foundation (to B.T. Kile), and the Cancer Council of Victoria (to D. Metcalf); the Australian Cancer Research Foundation, the Australian Phenomics Network, and a Victorian State Government Operational Infrastructure Support grant.

The authors declare no competing financial interests.

Submitted: 20 December 2014

Accepted: 21 April 2015

\section{REFERENCES}

Agostini, L., F. Martinon, K. Burns, M.F. McDermott, P.N. Hawkins, and J. Tschopp. 2004. NALP3 forms an IL-1 $\beta$-processing inflammasome with increased activity in Muckle-Wells autoinflammatory disorder. Immunity. 20:319-325. http://dx.doi.org/10.1016/S1074-7613(04)00046-9

Boyden, E.D., and W.F. Dietrich. 2006. Nalp1b controls mouse macrophage susceptibility to anthrax lethal toxin. Nat. Genet. 38:240-244. http://dx.doi.org/10.1038/ng1724

Brydges, S.D., L. Broderick, M.D. McGeough, C.A. Pena, J.L. Mueller, and H.M. Hoffman. 2013. Divergence of IL-1, IL-18, and cell death in NLRP3 inflammasomopathies. J. Clin. Invest. 123:4695-4705. http:// dx.doi.org/10.1172/JCI71543

Caso, F., D. Rigante, A. Vitale, O.M. Lucherini, L. Costa, M. Atteno, A. Compagnone, P. Caso, B. Frediani, M. Galeazzi, et al. 2013. Monogenic 
autoinflammatory syndromes: state of the art on genetic, clinical, and therapeutic issues. Int. J. Rheumatol. http://dx.doi.org/10.1155/2013/ 513782

Ceballos-Olvera, I., M. Sahoo, M.A. Miller, L. Del Barrio, and F. Re. 2011. Inflammasome-dependent pyroptosis and IL-18 protect against Burkholderia pseudomallei lung infection while IL-1 $\beta$ is deleterious. PLoS Pathog. 7:e1002452. http://dx.doi.org/10.1371/journal.ppat.1002452

Chae, J.J., H.D. Komarow, J. Cheng, G. Wood, N. Raben, P.P. Liu, and D.L. Kastner. 2003. Targeted disruption of pyrin, the FMF protein, causes heightened sensitivity to endotoxin and a defect in macrophage apoptosis. Mol. Cell. 11:591-604. http://dx.doi.org/10.1016/S10972765(03)00056-X

Chae, J.J., Y.H. Cho, G.S. Lee, J. Cheng, P.P. Liu, L. Feigenbaum, S.I Katz, and D.L. Kastner. 2011. Gain-of-function Pyrin mutations induce NLRP3 protein-independent interleukin- $1 \beta$ activation and severe autoinflammation in mice. Immunity. 34:755-768. http://dx.doi.org/10 $.1016 / \mathrm{j}$. immuni.2011.02.020

Dalton, D.K., S. Pitts-Meek, S. Keshav, I.S. Figari, A. Bradley, and T.A. Stewart. 1993. Multiple defects of immune cell function in mice with disrupted interferon- $\gamma$ genes. Science. 259:1739-1742. http://dx.doi.org/ $10.1126 /$ science. 8456300

Elinav, E., T. Strowig, A.L. Kau, J. Henao-Mejia, C.A. Thaiss, C.J. Booth, D.R. Peaper, J. Bertin, S.C. Eisenbarth, J.I. Gordon, and R.A. Flavell. 2011. NLRP6 inflammasome regulates colonic microbial ecology and risk for colitis. Cell. 145:745-757. http://dx.doi.org/10.1016/j.cell.2011 .04 .022

Franchi, L., A. Amer, M. Body-Malapel, T.D. Kanneganti, N. Ozören, R. Jagirdar, N. Inohara, P. Vandenabeele, J. Bertin, A. Coyle, et al. 2006. Cytosolic flagellin requires Ipaf for activation of caspase- 1 and interleukin $1 \beta$ in salmonella-infected macrophages. Nat. Immunol. 7:576-582. http://dx.doi.org/10.1038/ni1346

Ghayur, T., S. Banerjee, M. Hugunin, D. Butler, L. Herzog, A. Carter, L. Quintal, L. Sekut, R. Talanian, M. Paskind, et al. 1997. Caspase-1 processes IFN- $\boldsymbol{\gamma}$-inducing factor and regulates LPS-induced IFN- $\boldsymbol{\gamma}$ production. Nature. 386:619-623. http://dx.doi.org/10.1038/386619a0

Gouin, E., M.D.Welch, and P. Cossart. 2005. Actin-based motility of intracellular pathogens. Curr. Opin. Microbiol. 8:35-45. http://dx.doi.org/10.1016/ j.mib.2004.12.013

Gu, Y., K. Kuida, H. Tsutsui, G. Ku, K. Hsiao, M.A. Fleming, N. Hayashi, K. Higashino, H. Okamura, K. Nakanishi, et al. 1997. Activation of interferon- $\gamma$ inducing factor mediated by interleukin- $1 \beta$ converting enzyme. Science. 275:206-209. http://dx.doi.org/10.1126/science.275.5297.206

Haznedaroglu, S., M.A. Oztürk, B. Sancak, B. Goker, A.M. Onat, N. Bukan, I. Ertenli, S. Kiraz, and M. Calguneri. 2005. Serum interleukin 17 and interleukin 18 levels in familial Mediterranean fever. Clin. Exp. Rheumatol. 23:S77-S80.

Hornung, V., A. Ablasser, M. Charrel-Dennis, F. Bauernfeind, G. Horvath, D.R. Caffrey, E. Latz, and K.A. Fitzgerald. 2009. AIM2 recognizes cytosolic dsDNA and forms a caspase-1-activating inflammasome with ASC. Nature. 458:514-518. http://dx.doi.org/10.1038/nature07725

Jung, S., D. Unutmaz, P. Wong, G. Sano, K. De los Santos, T. Sparwasser, S. Wu, S. Vuthoori, K. Ko, F. Zavala, et al. 2002. In vivo depletion of $\mathrm{CD} 11 \mathrm{c}^{+}$dendritic cells abrogates priming of $\mathrm{CD}^{+} \mathrm{T}$ cells by exogenous cell-associated antigens. Immunity. 17:211-220. http://dx.doi .org/10.1016/S1074-7613(02)00365-5

Kayagaki, N., S. Warming, M. Lamkanfi, L. Vande Walle, S. Louie, J. Dong, K. Newton, Y. Qu, J. Liu, S. Heldens, et al. 2011. Non-canonical inflammasome activation targets caspase-11. Nature. 479:117-121. http:// dx.doi.org/10.1038/nature10558

Keller, M., A. Rüegg, S. Werner, and H.D. Beer. 2008. Active caspase-1 is a regulator of unconventional protein secretion. Cell. 132:818-831. http://dx.doi.org/10.1016/j.cell.2007.12.040

Kile, B.T., A.D. Panopoulos, R.A. Stirzaker, D.F. Hacking, L.H. Tahtamouni, T.A. Willson, L.A. Mielke, K.J. Henley, J.G. Zhang, I.P. Wicks, et al. 2007. Mutations in the cofilin partner Aip1/Wdr1 cause autoinflammatory disease and macrothrombocytopenia. Blood. 110:2371-2380. http://dx.doi.org/10.1182/blood-2006-10-055087

Leung, B.P., S. Culshaw, J.A. Gracie, D. Hunter, C.A. Canetti, C. Campbell, F. Cunha, F.Y. Liew, and I.B. McInnes. 2001. A role for IL-18 in neutrophil activation. J. Immunol. 167:2879-2886. http://dx.doi.org/ 10.4049/jimmunol.167.5.2879

Li, J., W.M. Brieher, M.L. Scimone, S.J. Kang, H. Zhu, H. Yin, U.H. von Andrian, T. Mitchison, and J. Yuan. 2007. Caspase-11 regulates cell migration by promoting Aip1-Cofilin-mediated actin depolymerization. Nat. Cell Biol. 9:276-286. http://dx.doi.org/10.1038/ncb1541

Li, P., H. Allen, S. Banerjee, S. Franklin, L. Herzog, C. Johnston, J. McDowell, M. Paskind, L. Rodman, J. Salfeld, et al. 1995. Mice deficient in IL-1 $\beta$-converting enzyme are defective in production of mature IL-1 $\beta$ and resistant to endotoxic shock. Cell. 80:401-411. http://dx.doi .org/10.1016/0092-8674(95)90490-5

Lieschke, G.J., D. Grail, G. Hodgson, D. Metcalf, E. Stanley, C. Cheers, K.J. Fowler, S. Basu, Y.F. Zhan, and A.R. Dunn. 1994. Mice lacking granulocyte colony-stimulating factor have chronic neutropenia, granulocyte and macrophage progenitor cell deficiency, and impaired neutrophil mobilization. Blood. 84:1737-1746.

Man, S.M., A. Ekpenyong, P. Tourlomousis, S. Achouri, E. Cammarota, K. Hughes, A. Rizzo, G. Ng, J.A. Wright, P. Cicuta, et al. 2014. Actin polymerization as a key innate immune effector mechanism to control Salmonella infection. Proc. Natl. Acad. Sci. USA. 111:17588-17593. http://dx.doi.org/10.1073/pnas.1419925111

Mansfield, E., J.J. Chae, H.D. Komarow, T.M. Brotz, D.M. Frucht, I. Aksentijevich, and D.L. Kastner. 2001. The familial Mediterranean fever protein, pyrin, associates with microtubules and colocalizes with actin filaments. Blood. 98:851-859. http://dx.doi.org/10.1182/blood .V98.3.851

Mariathasan, S., K. Newton, D.M. Monack, D. Vucic, D.M. French, W.P. Lee, M. Roose-Girma, S. Erickson, and V.M. Dixit. 2004. Differential activation of the inflammasome by caspase- 1 adaptors ASC and Ipaf. Nature. 430:213-218. http://dx.doi.org/10.1038/nature02664

Martinon, F., N. Holler, C. Richard, and J. Tschopp. 2000. Activation of a pro-apoptotic amplification loop through inhibition of NF-אB-dependent survival signals by caspase-mediated inactivation of RIP. FEBS Lett. 468:134-136. http://dx.doi.org/10.1016/S0014-5793(00)01212-6

Martinon, F., K. Burns, and J. Tschopp. 2002. The inflammasome: a molecular platform triggering activation of inflammatory caspases and processing of proIL- $\beta$. Mol. Cell. 10:417-426. http://dx.doi.org/10.1016 S1097-2765(02)00599-3

Martinon, F., V. Pétrilli, A. Mayor, A. Tardivel, and J. Tschopp. 2006. Gout-associated uric acid crystals activate the NALP3 inflammasome. Nature. 440:237-241. http://dx.doi.org/10.1038/nature04516

Masters, S.L., A. Simon, I. Aksentijevich, and D.L. Kastner. 2009. Horror autoinflammaticus: the molecular pathophysiology of autoinflammatory disease. Annu. Rev. Immunol. 27:621-668. http://dx.doi.org/10.1146/ annurev.immunol.25.022106.141627

Masters, S.L., A. Dunne, S.L. Subramanian, R.L. Hull, G.M. Tannahill, F.A. Sharp, C. Becker, L. Franchi, E. Yoshihara, Z. Chen, et al. 2010. Activation of the NLRP3 inflammasome by islet amyloid polypeptide provides a mechanism for enhanced IL-1 $\beta$ in type 2 diabetes. Nat. Immunol. 11:897-904. http://dx.doi.org/10.1038/ni.1935

Masters, S.L., M. Gerlic, D. Metcalf, S. Preston, M. Pellegrini, J.A. O’Donnell, K. McArthur, T.M. Baldwin, S. Chevrier, C.J. Nowell, et al. 2012. NLRP1 inflammasome activation induces pyroptosis of hematopoietic progenitor cells. Immunity. 37:1009-1023. http://dx.doi .org/10.1016/j.immuni.2012.08.027

Metcalf, D. 1985. The granulocyte-macrophage colony-stimulating factors. Science. 229:16-22. http://dx.doi.org/10.1126/science.2990035

Müller, A.J., C. Hoffmann, and W.D. Hardt. 2010. Caspase-1 activation via Rho GTPases: a common theme in mucosal infections? PLoS Pathog. 6:e1000795. http://dx.doi.org/10.1371/journal.ppat.1000795

Netea, M.G., C.A. Nold-Petry, M.F. Nold, L.A. Joosten, B. Opitz, J.H. van der Meer, F.L. van de Veerdonk, G. Ferwerda, B. Heinhuis, I. Devesa, et al. 2009. Differential requirement for the activation of the inflammasome for processing and release of IL-1 $\beta$ in monocytes and macrophages. Blood. 113:2324-2335. http://dx.doi.org/10.1182/blood-2008-03-146720

Okamura, H., H. Tsutsi, T. Komatsu, M. Yutsudo, A. Hakura, T. Tanimoto, K. Torigoe, T. Okura, Y. Nukada, K. Hattori, et al. 1995. Cloning of a new cytokine that induces IFN- $\gamma$ production by T cells. Nature. 378:88-91. http://dx.doi.org/10.1038/378088a0 
Özkaya, N., and F. Yalçinkaya. 2003. Colchicine treatment in children with familial Mediterranean fever. Clin. Rheumatol. 22:314-317. http:// dx.doi.org/10.1007/s10067-003-0739-9

Patel, S.R., J.H. Hartwig, and J.E. Italiano Jr. 2005. The biogenesis of platelets from megakaryocyte proplatelets. J. Clin. Invest. 115:3348-3354. http://dx.doi.org/10.1172/JCI26891

Pfeffer, K., T. Matsuyama, T.M. Kündig, A. Wakeham, K. Kishihara, A Shahinian, K. Wiegmann, P.S. Ohashi, M. Krönke, and T.W. Mak. 1993 Mice deficient for the $55 \mathrm{kd}$ tumor necrosis factor receptor are resistant to endotoxic shock, yet succumb to L. monocytogenes infection. Cell. 73:457-467. http://dx.doi.org/10.1016/0092-8674(93) 90134-C

Richards, N., P. Schaner, A. Diaz, J. Stuckey, E. Shelden, A. Wadhwa, and D.L. Gumucio. 2001. Interaction between pyrin and the apoptotic speck protein (ASC) modulates ASC-induced apoptosis. J. Biol. Chem. 276:39320-39329. http://dx.doi.org/10.1074/jbc.M104730200

Schroder, K., and J. Tschopp. 2010. The inflammasomes. Cell. 140:821832. http://dx.doi.org/10.1016/j.cell.2010.01.040

Seshadri, S., M.D. Duncan, J.M. Hart, M.A. Gavrilin, and M.D. Wewers 2007. Pyrin levels in human monocytes and monocyte-derived macrophages regulate IL-1 $\beta$ processing and release. J. Immunol. 179:12741281. http://dx.doi.org/10.4049/jimmunol.179.2.1274

Spector, I., N.R. Shochet, Y. Kashman, and A. Groweiss. 1983. Latrunculins: novel marine toxins that disrupt microfilament organization in cultured cells. Science. 219:493-495. http://dx.doi.org/10.1126/science .6681676

Spector, I., N.R. Shochet, D. Blasberger, andY. Kashman. 1989. Latrunculinsnovel marine macrolides that disrupt microfilament organization and affect cell growth: I. Comparison with cytochalasin D. Cell Motil. Cytoskeleton. 13:127-144. http://dx.doi.org/10.1002/cm.970130302

Srinivasula, S.M., J.L. Poyet, M. Razmara, P. Datta, Z. Zhang, and E.S. Alnemri 2002. The PYRIN-CARD protein ASC is an activating adaptor for caspase-1.J. Biol. Chem. 277:21119-21122. http://dx.doi.org/10.1074/ jbc.C200179200
Takeda, K., H. Tsutsui, T. Yoshimoto, O. Adachi, N. Yoshida, T. Kishimoto, H. Okamura, K. Nakanishi, and S. Akira. 1998. Defective NK cell activity and Th1 response in IL-18-deficient mice. Immunity. 8:383-390. http://dx.doi.org/10.1016/S1074-7613(00)80543-9

The International FMF Consortium. 1997. Ancient missense mutations in a new member of the RoRet gene family are likely to cause familial Mediterranean fever. Cell. 90:797-807. http://dx.doi.org/10.1016/ S0092-8674(00)80539-5

Thomas, H.E., W. Irawaty, R. Darwiche, T.C. Brodnicki, P. Santamaria, J. Allison, and T.W. Kay. 2004. IL-1 receptor deficiency slows progression to diabetes in the NOD mouse. Diabetes. 53:113-121. http://dx doi.org/10.2337/diabetes.53.1.113

Ushio, S., M. Namba, T. Okura, K. Hattori, Y. Nukada, K. Akita, F. Tanabe, K. Konishi, M. Micallef, M. Fujii, et al. 1996. Cloning of the cDNA for human IFN- $\gamma$-inducing factor, expression in Escherichia coli, and studies on the biologic activities of the protein. J. Immunol. 156:4274-4279.

van Rooijen, N., and R. van Nieuwmegen. 1984. Elimination of phagocytic cells in the spleen after intravenous injection of liposome-encapsulated dichloromethylene diphosphonate. An enzyme-histochemical study. Cell Tissue Res. 238:355-358. http://dx.doi.org/10.1007/BF00217308

Waite, A.L., P. Schaner, C. Hu, N. Richards, B. Balci-Peynircioglu, A. Hong, M. Fox, and D.L. Gumucio. 2009. Pyrin and ASC co-localize to cellular sites that are rich in polymerizing actin. Exp. Biol. Med. (Maywood). 234:40-52. http://dx.doi.org/10.3181/0806-RM-184

Westwell-Roper, C., A. Dunne, M.L. Kim, C.B. Verchere, and S.L. Masters 2013. Activating the NLRP3 inflammasome using the amyloidogenic peptide IAPP. Methods Mol. Biol. 1040:9-18. http://dx.doi.org/10.1007/ 978-1-62703-523-1_2

Wittmann, M., A. Macdonald, and J. Renne. 2009. IL-18 and skin inflammation. Autoimmun. Rev. 9:45-48. http://dx.doi.org/10.1016/j.autrev.2009.03.003

Xu, H., J. Yang, W. Gao, L. Li, P. Li, L. Zhang, Y.N. Gong, X. Peng, J.J. $\mathrm{Xi}, \mathrm{S}$. Chen, et al. 2014. Innate immune sensing of bacterial modifications of Rho GTPases by the Pyrin inflammasome. Nature. 513:237241. http://dx.doi.org/10.1038/nature13449 